\title{
Novel anti-angiogenic agents for colorectal cancer. Are we moving on?
}

\author{
Alexios S. Strimpakos ${ }^{1}$, Muhammad W. Saif ${ }^{2}$, Kostas N. Syrigos ${ }^{1}$ \\ 1. Oncology Unit, 3rd Dept of Medicine, University of Athens, Sotiria General Hospital, Athens, Greece. 2. Division of \\ Hematology/Oncology, Tufts Medical Center, Tufts University School of Medicine, Boston, USA
}

Correspondence: Kostas Syrigos. Address: Oncology Unit, 3rd Dept of Medicine, Athens University School of Medicine Building Z, Sotiria General Hospital, Mesogeion 152, 11527 Athens, Greece. E-mail: ksyrigos@med.uoa.gr; knsyrigos@usa.net

Received: August 27, 2012

Accepted: September 24, 2012

URL: http://dx.doi.org/10.5430/jst.v3n1p1

Online Published: December 9, 2012

DOI : $10.5430 /$ jst.v3n1p1

\section{Introduction}

Tumours depend greatly on blood supply to grow, spread and metastasise. It has been proposed, for a long time now, that angiogenesis and neo-vasculature development are present in tumours ${ }^{[1,2]}$. Angiogenesis is subject to regulation by a number of pro-angiogenic growth factors such as the vascular endothelial growth factors (VEGFs), angiopoetin, platelet derived growth factor (PDGF), placental growth factor (PlGF) and others, which are counteracted by proangiogenic growth factors such as angiostatin, transforming growth factor-beta (TGF- $\beta$ ) and others ${ }^{[1,3]}$. Among those growth factors, the most studied and associated with tumour growth and neo-angiogenesis is the family of the vascular endothelial growth factor (VEGF), which includes VEGF-A (the archetypal member, often called as VEGF), placental growth factor (PIGF), VEGF-B, VEGF-C, and VEGF-D (known also as c-Fos-induced growth factor, FIGF), and the viral VEGF-E. These growth factors exert their biological function through the VEGF transmembrane receptors VEGFR-1, -2 and -3 . In particular, VEGF binds to VEGFR-1 and -2, VEGF-B and PIGF only to VEGFR-1, VEGF-C and VEGF-D to VEGFR-2 and $-3^{[4-8]}$.

Based on this preclinical evidence, novel agents targeting the tumour vasculature at various levels (antibodies binding growth factor ligands or blocking their receptors, small molecules inhibiting phosphorylation of tyrosine kinase of growth factors, multi-kinase inhibitors) have been developed and tested in clinical trials over the last decade (Figure 1) ${ }^{\text {[9-13] }}$.

A lot of agents have been tested, but until recently only the recombinant humanised monoclonal antibody against the vascular endothelial growth factor-A (VEGF) bevacizumab had showed clinical efficacy in advanced colorectal cancer (CRC), improving response rate, progression free and overall survival as demonstrated in many trials in the first or second line treatment ${ }^{[14,15]}$. This benefit was present only when bevacizumab was added to a chemotherapy agent. The first randomised, placebo controlled clinical trial, that led to approval of this agent by the authorities, was conducted in 2004 by Hurwitz et al who showed that addition of bevacizumab to irinotecan, 5-fluorouracil and leucovorin (IFL) regimen in the first line CRC setting improved survival rate by almost 5 months ${ }^{[16]}$. Subsequently, other studies have confirmed the efficacy of bevacizumab in various combinations with irinotecan, oxaliplatin and fluoropyrimidines (5-fluorouracil or capecitabine) in the first or second line setting ${ }^{[17-19]}$. Unfortunately, the majority of patients do not show benefit from the addition of this antibody, and significant research on the potential mechanisms of resistance or escape from bevacizumab actions is being undertaken. One of the hypotheses suggested that upregulation of other angiogenic proteins such as PlGF 
or VEGF-B might occur (especially secondary to VEGF-A blockage by bevacizumab) and might maintain the stimulus to VEGF signalling pathway. Since 2004, a large number of studies testing various anti-angiogenic agents (antibodies or small molecules) on metastatic colorectal cancer were conducted with disappointing results, until recently that two novel agents targeting vasculature have showed some benefit on metastatic CRC. (Table 1)

Figure 1. The VEGFR pathway and targets of treatment

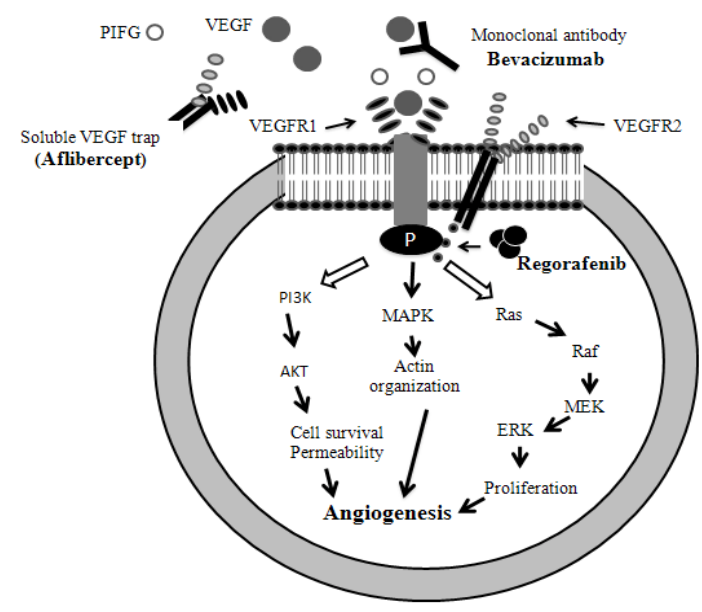

Table 1. Effective anti-angiogenic biological agents tested in phase III studies in advanced colorectal cancer

\begin{tabular}{|c|c|c|c|}
\hline Agent & Mode of action & Approved indication & Added survival benefit (mo) \\
\hline \multirow{3}{*}{ Bevacizumab } & & $-1^{\text {st }}$ line + CT & PFS: 4.4 \\
\hline & Recombinant monoclonal antibody & & OS: 4.7 \\
\hline & & $-2^{\text {nd }}$ line $+C T$ & \\
\hline Aflibercept & $\begin{array}{l}\text { Fusion protein consisted from the IgG1 } \\
\text { portions of VEGFR1 \& } 2 \text { that binds } \\
\text { circulating VEGF (VEGF trap) }\end{array}$ & $2^{\text {nd }}$ line + FOLFIRI & $\begin{array}{l}\text { PFS: } 2.23 \\
\text { OS: } 1.44\end{array}$ \\
\hline Regorafenib & $\begin{array}{l}\text { Multi kinase inhibitor (mainly } \\
\text { VEGFR1-2-3, TIE2, PDGFR, c-KIT, } \\
\text { RET) }\end{array}$ & $\begin{array}{l}3^{\text {rd }} \text { line treatment as } \\
\text { monotherapy }\end{array}$ & $\begin{array}{l}\text { PFS: } 0.2 \\
\text { OS: } 1.4\end{array}$ \\
\hline
\end{tabular}

Abbreviations: CT; chemotherapy, OS; overall survival, PDGFR; platelets derived growth factor receptor, PFS; progression free survival, TIE2; tyrosine kinase with immunoglobulin and EGF homology domain 2, VEGF; vascular endothelial growth factor

The first one, aflibercept (AVE0005), a fully humanized recombinant fusion protein, fuses the extracellular domain 2 from VEGFR-1 and the extracellular domain 3 from VEGFR-2, with the constant region of the human immunoglobulin G1 (IgG1). This fusion antibody mainly binds the circulating VEGF-A ligand, with higher affinity than the native VEGF receptors, and secondly traps the ligands VEGF-B, and PIGF 1and 2 which are often upregulated in colon cancer inhibiting thus VEGF pathway and angiogenesis ${ }^{[20]}$. Following encouraging results from phase II clinical studies, a phase III double blind randomized placebo controlled study on second line colorectal cancer treatment tested the benefit of aflibercept in combination with FOLFIRI (5-fluorouracil, leucovorin and irinotecan) regimen ${ }^{[21]}$. The study recruited 1226 patients who were randomized to either FOLFIRI plus aflibercept $(n=614)$ or FOLFIRI plus placebo $(n=612)$. The primary endpoint of the study was overall survival and secondary endpoints were progression free survival and response rate. The experimental arm was better for median OS (13.50 months versus 12.06 months, $p=0.0032$ ), PFS (6.90 versus 4.67 months, $p=0.00007$ ) and overall response rate $(19.8 \%$ versus $11.1 \%, p=0.0001)$. As far as toxicity was concerned, more patients on the aflibercept arm experienced grade 3 and 4 toxicities, especially diarrhea, asthenia, mucositis, infections, hypertension, abdominal pains, neutropenia and proteinuria which led to more treatment discontinuations than the placebo group (26.6\% 
versus $12.1 \%)^{[21]}$. An important observation was that the benefit from aflibercept was irrelevant to whether patients had previously received bevacizumab or not. This somehow confirms that other upregulated and important for tumour growth and angiogenesis molecules (such as VEGF-B and PlGF) confer resistance to bevacizumab and their inhibition is associated with clinical benefit.

The second novel agent, that recently attracted attention in advanced CRC, is regorafenib (BAY 73-4506), an oral multikinase inhibitor of the extracellular vascular receptors VEGFR1-3, the stromal platelet-derived growth factor receptor- $\beta$ (PDGFR-beta) and fibroblast growth factor receptor 1 (FGFR-1) as well as some oncogenic cytoplasmic kinases (KIT, RET, B-RAF). Regorafenib was tested on the CORRECT trial (Patients with metastatic colorectal cancer treated with regorafenib or placebo after failure of standard therapy), an international, multicenter, randomized, double-blind study that enrolled 760 patients with mCRC refractory to standard treatments. Patients received $160 \mathrm{mg}$ of regorafenib (or placebo) once a day for three weeks followed by one week off plus best supportive care (BSC). The primary endpoint of the study was overall survival whereas secondary endpoints included progression-free survival (PFS), response rate and disease control rate (DCR). The study's results were recently announced at the 2012 American Society of Clinical Oncology (ASCO) Gastrointestinal Symposium, after an early closure of the study following an interim review by an Independent Data Monitoring Committee which recommended unblinding of the study based on significant difference on survival between the two study arms. Indeed, the experimental arm (regorafenib plus BSC) showed a statistically significant improvement in median overall survival (OS) by $29 \%$ or 1.4 months (6.4 versus 5.0 months) (HR=0.77, $p=0.0052$ ) compared to placebo plus BSC. Secondary endpoints were also met with a median PFS of 1.9 months in the regorafenib arm versus 1.7 months in the placebo arm ( $\mathrm{HR}=0.49, p<0.000001)$, and DCR of $44.8 \%$ versus $15.3 \%$ respectively, whereas response rate was very low in both arms (1.0\% and $0.6 \%)$. The toxicity profile of this agent was similar to the other two aforementioned antivascular drugs with asthenia, hypertension, anorexia, rash but also diarrhoea, mucositis and hand-foot syndrome being the commonest but manageable side effects ${ }^{[22]}$.

Based on the above findings, one could be pleased with the fact that many years after the success of bevacizumab and following many unsuccessful trials on novel anti-angiogenic agents, we have large randomized studies providing evidence of efficacy of new drugs on the second line and refractory CRC. There are several positive points that one could take out from these two recent studies. Most importantly, the hypothesis that multiple molecular events take place simultaneously on the cellular level explains the reasons why aiming at a single aberration or target (as with bevacizumab) fails to provide very positive clinical results, and why agents targeting multiple molecules (such as aflibercept and regorafenib) show some efficacy, in previously treated patients, even with an anti-vascular agent. Furthermore, the efficacy of these novel drugs in second-on metastatic setting where tumors are particularly resistant and the disease less controlled, allows some optimism that testing in the first or second line CRC and in various combination might be more effective. Of course, at some point these agents will have to test their strengths against bevacizumab and then we will be able to draw conclusions regarding the benefit of targeting upfront molecules at different levels of the pathway, in naïve patients, rather than doing it when the disease has somehow become resistant.

Nonetheless, in the current times of financial restrain, survival benefits by one to two months using these very expensive drugs raise doubts about the clinical significance and meaningfulness and the real impact on the natural course of an incurable disease. Of course, this very important aspect will be taken into account before authorities' give full approval of these two agents in everyday practice. In conclusion, now more than ever biomarkers of efficacy of anti-vascular agents are needed in order to identify those patients who might benefit the most and thus improve our results but also keep the cost at reasonable levels. The translational challenges on this area remain unmet and exciting and more research is worth pursuing by both industry and scientists.

\section{References}

[1] Folkman J. What is the evidence that tumors are angiogenesis dependent? J Natl Cancer Inst. 1990; 82(1): 4-6. PMid:1688381 http://dx.doi.org/10.1093/jnci/82.1.4

Published by Sciedu Press 
[2] Folkman J. Tumor angiogenesis: therapeutic implications. N Engl J Med. 1971; 285(21): 1182-1186. PMid:4938153 http://dx.doi.org/10.1056/NEJM197111182852108

[3] Rosen LS. Clinical experience with angiogenesis signaling inhibitors: focus on vascular endothelial growth factor (VEGF) blockers. Cancer Control. 2002; 9(2 Suppl): 36-44.

[4] Kukk E, Lymboussaki A, Taira S, Kaipainen A, Jeltsch M, Joukov V et al. VEGF-C receptor binding and pattern of expression with VEGFR-3 suggests a role in lymphatic vascular development. Development. 1996; 122(12): 3829-3837. PMid:9012504

[5] Plate KH, Breier G, Weich HA, Risau W. Vascular endothelial growth factor is a potential tumour angiogenesis factor in human gliomas in vivo. Nature. 1992; 359(6398): 845-848. PMid:1279432 http://dx.doi.org/10.1038/359845a0

[6] Paavonen K, Horelli-Kuitunen N, Chilov D, Kukk E, Pennanen S, Kallioniemi OP et al. Novel human vascular endothelial growth factor genes VEGF-B and VEGF-C localize to chromosomes 11q13 and 4q34, respectively. Circulation. 1996; 93(6): $1079-1082$. PMid:8653826 http://dx.doi.org/10.1161/01.CIR.93.6.1079

[7] Achen MG, Jeltsch M, Kukk E, Makinen T, Vitali A, Wilks AF et al. Vascular endothelial growth factor D (VEGF-D) is a ligand for the tyrosine kinases VEGF receptor 2 (Flk1) and VEGF receptor 3 (Flt4). Proc Natl Acad Sci USA. 1998; 95(2): 548-553. PMid:9435229 http://dx.doi.org/10.1073/pnas.95.2.548

[8] Andre T, Kotelevets L, Vaillant JC, Coudray AM, Weber L, Prevot S et al. Vegf, Vegf-B, Vegf-C and their receptors KDR, FLT-1 and FLT-4 during the neoplastic progression of human colonic mucosa. Int J Cancer. 2000; 86(2): 174-181. http://dx.doi.org/10.1002/(SICI)1097-0215(20000415)86:2<174::AID-IJC5>3.0.CO;2-E

[9] Shaheen RM, Davis DW, Liu W, Zebrowski BK, Wilson MR, Bucana CD et al. Antiangiogenic therapy targeting the tyrosine kinase receptor for vascular endothelial growth factor receptor inhibits the growth of colon cancer liver metastasis and induces tumor and endothelial cell apoptosis. Cancer Res. 1999; 59(21): 5412-5416. PMid:10554007

[10] Kabbinavar F, Hurwitz HI, Fehrenbacher L, Meropol NJ, Novotny WF, Lieberman G et al. Phase II, randomized trial comparing bevacizumab plus fluorouracil (FU)/leucovorin (LV) with FU/LV alone in patients with metastatic colorectal cancer. J Clin Oncol. 2003; 21(1): 60-65. PMid:12506171 http://dx.doi.org/10.1200/JCO.2003.10.066

[11] Saltz LB, Rosen LS, Marshall JL, Belt RJ, Hurwitz HI, Eckhardt SG et al. Phase II trial of sunitinib in patients with metastatic colorectal cancer after failure of standard therapy. J Clin Oncol. 2007; 25(30): 4793-4799. PMid:17947727 http://dx.doi.org/10.1200/JCO.2007.12.8637

[12] Tew WP, Gordon M, Murren J, Dupont J, Pezzulli S, Aghajanian C et al. Phase 1 study of aflibercept administered subcutaneously to patients with advanced solid tumors. Clin Cancer Res. 2010; 16(1): 358-366. PMid:20028764 http://dx.doi.org/10.1158/1078-0432.CCR-09-2103

[13] Strumberg D, Scheulen ME, Schultheis B, Richly H, Frost A, Buchert M et al. Regorafenib (BAY 73-4506) in advanced colorectal cancer: a phase I study. Br J Cancer. 2012; 106(11): 1722-1727. PMid:22568966 http://dx.doi.org/10.1038/bjc.2012.153

[14] Grothey A, Sugrue MM, Purdie DM, Dong W, Sargent D, Hedrick E et al. Bevacizumab beyond first progression is associated with prolonged overall survival in metastatic colorectal cancer: results from a large observational cohort study (BRiTE). J Clin Oncol. 2008; 26(33): 5326-5334. PMid:18854571 http://dx.doi.org/10.1200/JCO.2008.16.3212

[15] Van CE, Rivera F, Berry S, Kretzschmar A, Michael M, DiBartolomeo M et al. Safety and efficacy of first-line bevacizumab with FOLFOX, XELOX, FOLFIRI and fluoropyrimidines in metastatic colorectal cancer: the BEAT study. Ann Oncol. 2009; 20(11):1842-1847. PMid:19406901 http://dx.doi.org/10.1093/annonc/mdp233

[16] Hurwitz H, Fehrenbacher L, Novotny W, Cartwright T, Hainsworth J, Heim W et al. Bevacizumab plus irinotecan, fluorouracil, and leucovorin for metastatic colorectal cancer. N Engl J Med. 2004; 350(23): 2335-2342. PMid:15175435 http://dx.doi.org/10.1056/NEJMoa032691

[17] Kabbinavar FF, Hambleton J, Mass RD, Hurwitz HI, Bergsland E, Sarkar S. Combined analysis of efficacy: the addition of bevacizumab to fluorouracil/leucovorin improves survival for patients with metastatic colorectal cancer. J Clin Oncol. 2005; 23(16): 3706-3712. PMid:15867200 http://dx.doi.org/10.1200/JCO.2005.00.232

[18] Giantonio BJ, Catalano PJ, Meropol NJ, O'Dwyer PJ, Mitchell EP, Alberts SR et al. Bevacizumab in combination with oxaliplatin, fluorouracil, and leucovorin (FOLFOX4) for previously treated metastatic colorectal cancer: results from the Eastern Cooperative Oncology Group Study E3200. J Clin Oncol. 2007; 25(12): 1539-1544. PMid:17442997 http://dx.doi.org/10.1200/JCO.2006.09.6305

[19] Saltz LB, Clarke S, Diaz-Rubio E, Scheithauer W, Figer A, Wong R et al. Bevacizumab in combination with oxaliplatin-based chemotherapy as first-line therapy in metastatic colorectal cancer: a randomized phase III study. J Clin Oncol. 2008; 26(12): 2013-2019. PMid:18421054 http://dx.doi.org/10.1200/JCO.2007.14.9930

[20] Chu QS. Aflibercept (AVE0005): an alternative strategy for inhibiting tumour angiogenesis by vascular endothelial growth factors. Expert Opin Biol Ther. 2009; 9(2): 263-271. PMid:19236257 http://dx.doi.org/10.1517/14712590802666397 
[21] Van CE, Tabernero J, Lakomy R, Prenen H, Prausova J, Macarulla T et al. Addition of Aflibercept to Fluorouracil, Leucovorin, and Irinotecan Improves Survival in a Phase III Randomized Trial in Patients With Metastatic Colorectal Cancer Previously Treated With an Oxaliplatin-Based Regimen. J Clin Oncol. 2012.

[22] Grothey A, Sobrero AF, Siena S, Falcone A, Ychou M, Lenz HJ et al. Results of a phase III randomized, double-blind, placebo-controlled, multicenter trial (CORRECT) of regorafenib plus best supportive care (BSC) versus placebo plus BSC in patients (pts) with metastatic colorectal cancer (mCRC) who have progressed after standard therapies. J Clin Oncol (Meeting Abstracts). 2012; 30(4_suppl): LBA385. 